UDC 376:373:159.922.7

\title{
ATTITUDE OF SAMAGRA SHIKSHA ABHIYAN SPECIAL TEACHERS TOWARDS INCLUSION OF THE CHILDREN WITH DIVYANGJAN IN NAGPUR
}

\author{
AUTHOR'S DATA: \\ Madhavi Sharma, Dr., Associated professor \\ Faculty of Special Education, The ICFAI University Tripura, Agartala, India \\ Principal \\ Contacts: drmadhavi.sharma@iutripura.edu.in
}

\begin{abstract}
The rationale of the study is to analyze the "Samagra Shiksha Abhiyan Special Teachers attitude towards Inclusion of the Children with Divyangjan in Nagpur. The study is a descriptive research design used by survey method. The views of inclusive teachers in the areas of attitude towards concept of Inclusion, attitude towards strategies to improve Inclusion and attitude towards collaboration between inclusive teachers and regular teachers. The sample size of the study was 100 inclusive teachers' (male 50 and female 50), from Government schools working in Block Resource Centre under SSA, Nagpur. The results showed that there is no significance difference among the inclusive teachers towards Inclusion of the children with Divyangjan with respect to age, gender, educational qualifications and teaching experiences. Age, Hence the researcher has been rejected the hypotheses at 0.05 levels. As the study shows that attitude of inclusive teachers towards Inclusion of the children with Divyangjan was highly positive.
\end{abstract}

Key words: Divyangjan - Intellectual disability, Inclusion, Samagra Shiksha Abhiyan (SSA), inclusive teachers, general teachers, children with Divyangjan.

\section{INTRODUCTION}

The term Inclusion makes provision for learning of all children in the classroom. The general teacher becomes the facilitator. The general school adapts to the needs of every child in the classroom. The principle of Inclusion states that the general teacher should be the facilitator for learning (Bowman, 1986). This responsibility does not limit only to the classroom but goes much beyond it. Inclusion also envisages that general school would adapt to the needs of every 
child in the classroom. The UNESCO Resource pack was the first step in developing classroom strategies, which will benefit all children. Globally there is tremendous awareness about the importance of developing inclusive learning environments (Bowman, 1986).

We know that "those who learn together learn to live together". Inclusion means providing education to the children with disabilities in a regular class together with non-disabled children. No matter how the child's disability disabled may be, he will need some support and provisions over and above those which are regular schools has for the other children. One of the main features of Inclusion is the development of the capability of the regular education system to meet the educational needs of children with any kind of impairment. The term inclusive refers to the opportunity for persons with disability to participate fully in all the education, employment, recreational, community and domestic activities that typify every society (ILSMH, 1999).

Services are provided in Inclusion: There are three types of services required directly or indirectly for the children with disability in an Inclusion programs in India.

They are as follows,

1. Essential services: The general classroom teachers provide these services to disabled children e.g. consulting with special teachers, interacting with parents of disabled children, evaluation etc. When general classroom teachers provide these services, the child would be to get education in the general school even if there is no special teacher to attend to $\operatorname{him} /$ her.

2. Support services: These services provide by the qualified and trained special teacher. These teachers provide necessary material support and occasional academic support to children with disabilities and also provide the needed consultancy to regular classroom teachers e.g. identifying children with disabilities in the community, assisting general classroom teachers if needed, arranging aids and appliances, monitoring the progress of the child through classroom teachers.

3. Peripheral services: Agencies such as hospitals, rehabilitation centers, and nongovernment organizations etc. can provide these services such as identification, assessment, counseling, issuing medical reports, providing social benefits, counseling to parents etc.

According to the National Inclusion Directorate and DSSA, Inclusion has a range of benefits and all role- players are on the receiving end. 
Children experiencing barriers to learning:

- They can learn new skills through imitation.

- They are with peers from whom they can learn new social and real life skills that will equip them to live in their communities.

- They have an opportunity to develop friendships with typically developing children.

- They get access to education in their communities instead of being sent away to special schools or staying at home.

All other children:

- They are able to learn more realistic and accurate views about children experiencing barriers to learning.

- They can develop positive attitudes towards those different from them.

- They can learn from others who successfully achieve despite challenges in their way.

- Both slow and gifted learners can benefit from the inclusion of learners needing support to learn.

Families of children who experience barriers to learning:

- They will feel less isolated from the rest of the community.

- They will develop relationships with other families who can provide them with support.

- They can enjoy having their children at home during their school years without the need to send them away to special schools or hostels.

Families of the other children:

- Will develop relationships with families with children with disabilities and be able to make a contribution.

- Will be able to teach their children about individual differences and the need to accept those who are different.

Communities:

- They can economize by providing one program for all children rather than separate programs.

- People experiencing barriers to learning who have developed their full potential through effective education no longer are a burden to society but can make a contribution.

- Communities will learn to appreciate diversity in their midst 
Inclusive Teacher: An inclusive teacher is one who is able to teach all students in the Classroom. These Includes students who have learning disabilities, emotional Disabilities and Physical Disabilities. Being able to teach these Students means being able to make certain accommodations and adaptations so that learning is made easier (Cornoldi, Cesare, Terreni, Aiessandra et al., 1998; Colin, 2004). All students, even those without adisability need to be in an environment where they are able to learn best. In order for an inclusive teacher to do what is best for the Child, there is some collaboration that is required. There are a number of different personnel within the school to collaborate and each situation is different. Perhaps the first Person within the school for an inclusive teacher is to collaborate with regular education teachers' and the successful collaboration needs to be a positive experience. The first step to a successful collaboration is Cooperation and Understanding between the support personnel and the Classroom teacher. Both Sides must work to achieve the goal. This includes having planning time together, listening to each other's and making adjustments based on the Concerns.

The Government of India has launched Samagra Shiksha Abhiyan (S.S.A) for universalization of elementary Education (UEE). The program aims at providing useful a relevant elementary education in the age group of 6-14 years by 2010. The 86th constitutional Amendment, which has made free and compulsory education a right of all children from 614 years of age has given further trust to the goal of UEE. The objective of UEE cannot be achieved without including children with special needs under ambit of elementary education. The One of the focus areas of SSA is to increase access, enrolment, retention of all children and to reduce school drop outs. The project aims that education for all including children with different disabilities such as V.I., H.I., M.R, and associated problems. It is working effectively in primary education. The project facilitates school building constructing, developing educational resources, facilities for aids and appliances, conducing teachers training program for regular teachers, recruitment of resource teachers at the block level to meet and fulfill the special needs of children with disabilities in addition, orientation program for regular teachers are conducted on management of children with special needs in their classrooms.

Components of Education for Children with Special Needs in an inclusive setting

The interventions suggested under Inclusion are as follows:

- Awareness

- Necessary infrastructure for planning and management. 
- Early detection and identification.

- Functional and formal assessment.

- Educational placement

- Preparation of Individualized Educational Plan

- Aids and appliances

- Teacher training

- Resource support

- Strengthening of special schools

- Removal of architectural barriers

- Monitoring and evaluation.

Inclusion requires close collaboration between the regular class teachers and range of other people including inclusive teachers trained by S.S.A., Special educators, Resource teachers, teaching assistants, therapists and parents (Hofman, 1997; Fox \& Ysseidyke, 1997). There is need to investigate what inclusive teachers feel or think about Inclusion of the children with intellectual disability? What changes they want in present education system? Whether the Samagra Shiksha Abhiyan has deliberating the right form of education to the children with special needs? What are the attitudes they have towards Inclusion of the children with intellectual disability? In which area did they receive training through Samagra Shiksha Abhiyan? Is the duration of training being sufficient to them for dealing the children with Divyangjan in regular schools? Literature search on inclusive teachers in Indian context showed no evidence of research undertaken. The children with special needs are facing a lot due to the lack of special trained teachers in regular schools. For this the Samagra Shiksha Abhiyan has planned to train regular teachers in special education with the help of special professionals for inclusion the children with Divyangjan in regular schools but still there is a huge gap in their mind that How the children with Divyangjan can be taught along with non-disabled children in the classroom? So there is a need of this research study to know the present attitude among inclusive teachers trained by Samagra Shiksha Abhiyan towards Inclusion of the children with Divyangjanin regular school. This can give us insight to understand the attitude of inclusive teacher trained by Samagra Shiksha Abhiyan towards Inclusion of the children with intellectual disability, to enable us to take necessary steps to prepare the inclusive teachers to accept the concept in true sense of the term. Hence this research intends to engage a descriptive research design by understanding a survey study to investigate the attitude of inclusive 
teachers trained by the Samagra Shiksha Abhiyan towards Inclusion of the children with Divyangjan in regular school.

Attitude: Attitude refers to the Inclusive teachers' beliefs, feelings or thoughts and way of reaction towards the children with intellectual disability.

Special / Inclusive teachers: Inclusive teachers refers to that the training who received through Samagra Shiksha Abhiyan towards Inclusion.

Samagra Shiksha Abhiyan (S.S.A): Samagra Shiksha Abhiyan is an endeavor for Universalization of elementary education in India.

Inclusion: Inclusion denotes a student with disability unconditionally belonging to and having full membership of a regular classroom in a regular school and in his / her community. No child due to his / her disability is rejected by the regular school. It emphasis on zero rejection (Verma \& Verma, 1974; York \& Tundidor, 1995; Anthea \& Tricia, 2005).

Children with intellectual disability: Children with Divyangjan refer to children who have significantly sub-average, deficit in adaptive behavior and identified as Divyangjan by the inclusive teachers.

\section{LITERATURE REVIEW}

A study conducted by Paul et al. (2006) on sustainability of inclusive school reform covered individual interviews with 95 teachers and 16 administrators, working in middle schools in a large urban and sub-urban district in southeast Florida. One middle school was notably successful, having built its inclusion model on a foundation of previous reform and a school cultural characterized by shared decision making, collaboration and training. For four years, they studied Socrates and sustainability of its program. Inclusion was not sustained; the researchers' analysis of teacher and administration interviews reveals three primary factors that help explain why; leadership change, teacher turn over, and state and district assessment policy change, reduced support for the program, a by-product of the Primary factors, also contributed to the lack of sustainability (Rane, 1983; Scruggs \& Mastropieri, 1996). Guido (1990), studied educators' attitude towards the inclusion of severely/profoundly-disabled students in regular classrooms. The purpose of study was to investigate the relationship between professional educator's attitude and integration of severely /profoundly disabled students in regular classroom. The present research showed that increased specific special education knowledge and experience is a key factor in more 
favorite attitude towards case of placement of severely profound disabled students in regular educational classrooms. Formatting opportunities for regular/special educators to take advantage of specialized course appears to support integration efforts for more severely disabled students in regular classes (Guido, 1990; Praisner, 2003).

Soodak, Podell and Lehman (1998) conducted a study on elementary middle and high school general education teachers concerning their affective response to inclusion. The findings indicated that the affective responses were related to teacher attributes, student disability categories and school based conditions. Teachers who possessed low teaching efficacy, who lacked experience in teaching or who had low use of differentiated teaching practices and teacher collaboration were found to be less receptive to inclusion.

Minke et al. (1996) study on collaborative teaching in Inclusion practice setting found that general and special educators working collaboratively in inclusive settings had higher levels of personal efficacy and higher self-ratings of competence and satisfaction in teaching students with disabilities than general educators who taught in traditional classroom arrangements.

\section{MATERIALS AND METHODS}

The study is at finding out the attitude of inclusive teachers' trained by Samagra Shiksha Abhiyan towards Inclusion of the children with intellectual disability working in BRC under Nagpur District. It is descriptive study using survey method for collecting data to investigate the study. The sample for the study was selected 100 (50 were Female inclusive teachers and 50 were male inclusive teachers) who were working in Government Schools working in BRC under SSA, Nagpur. The random sampling technique was used for selection of the sample. A questionnaire was developed to collect the data from the respondents on " Samagra Shiksha Abhiyan Special Teachers attitude towards Inclusion of the Children with Divyangjan in Nagpur. The questionnaire consists of two parts. The part -A consists the demographic data of the respondents which includes the age, gender, educational qualifications, teaching experiences and number of days training programs received from the Samagra Shiksha Abhiyan, Nagpur. The Part-B consists of the questionnaire on attitude of inclusive teachers' trained by Samagra Shiksha Abhiyan towards Inclusion of the children with Divyangjan under various dimensions:

a) Attitude of Samagra Shiksha Abhiyan trained teachers towards the concept of Inclusion, 
b) Attitude towards strategies to improve Inclusion

c) Attitude towards collaboration between inclusive teachers and Regular Teachers.

d) Attitude towards resources and management in special education to improve Inclusion

The respondents were asked to respond by giving options of" Strongly Agree", "Agree" or "Disagree".

After pilot study it was decided to do main study on "Samagra Shiksha Abhiyan Special Teachers attitude towards Inclusion of the Children with Divyangjan in Nagpur District. Initially permission has been taken from project officer, Samagra Shiksha Abhiyan Nagpur, for collecting the data on the present study from Inclusive Teachers of the concern Government schools working under the Samagra Shiksha Abhiyan, Format for collecting demographic data of the respondent and questionnaire has been distributed among 100 inclusive teachers belongs to Government schools working in Block Resource Centre, Nagpur. The questionnaire was given by hand with necessary instructions and the purpose of the study has been explained to them. They filled the questionnaire in the presence of researcher and also asked them to go through each item carefully and to respond to each item in the form of Strongly Agree, Agree or Disagree. Sufficient time was given to the respondents to fill the questionnaire. The filled forms were collected from the respective subjects to analyze the data using appropriate statistical measures.

Statistical Measures: Appropriate statistical techniques were employed to analyze the data, the collected data was edited, coded and then enter against the identification numbers of each subject. The statistical analysis of the study consists of tabular representation of percentage, mean, standard deviation, independent t-tests.

\section{RESULTS AND DISCUSSION}

The analysis and interpretation of collected data were done on the basis of objectives of the study. The Figure 1 indicated that the item number 12 (20\%), 22 (25\%) and 24 (20\%) respectively have got less response and all other items got above $40 \%$ to $80 \%$ are positive attitude towards Inclusion of children with mental retardation. The results indicated that most of the inclusive teachers have positive towards Inclusion of the teachers with mental retardation. There is not much differences found with regard to the items. The mean and standard deviations of attitude of inclusive teachers towards Inclusion of the children with mental retardation was almost same. However, the results also reveal that the sample characteristics with respect to distribution 
of age between the two age group (20-40 years, 40-58 years) and the difference in mean scores is $78.5 \%$ and $21.5 \%$ respectively.

Figure 1. Items wise percentage on attitude of inclusive teachers towards Inclusion of the children with mental retardation

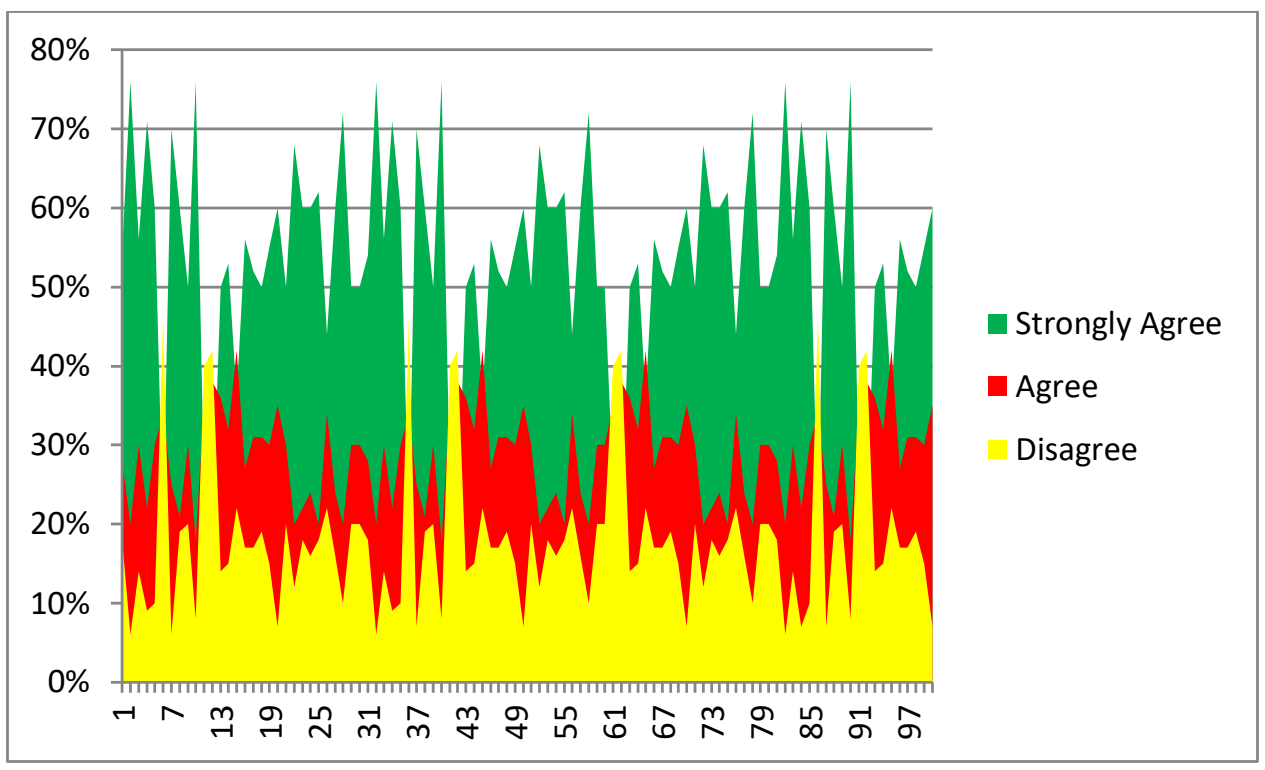

It indicates that there are more number of participants between the age groups 20 to 40 years and their attitude is positive towards inclusion similarly the distribution with respect to gender male $50 \%$ whereas female $50 \%$ and their attitude is positive towards inclusive of children with mental retardation.

The sample characteristics with respect to distribution with respect to educational qualifications between graduate and post graduate is $60 \%$ and $40 \%$ respectively. However, the distribution with regard to teaching experiences between 1 to 15 years and 15 to 30 years with valid percentage $72.5 \%$ and $27.5 \%$ respectively, therefore the frequency distribution of number of years of teaching experiences between the age group 15 to 30 years are less participants and their attitudes are also positive towards inclusion. The findings of study on attitude of inclusive teachers trained by Samagra Shiksha Abhiyan towards Inclusion of children with mental retardation with respect to variables such as age, gender, educational qualification and teaching experience are almost found positive attitude towards inclusion. 
Figure 2. Comparison Age Group, Gender, Education Qualification and Teaching Experiences within the group

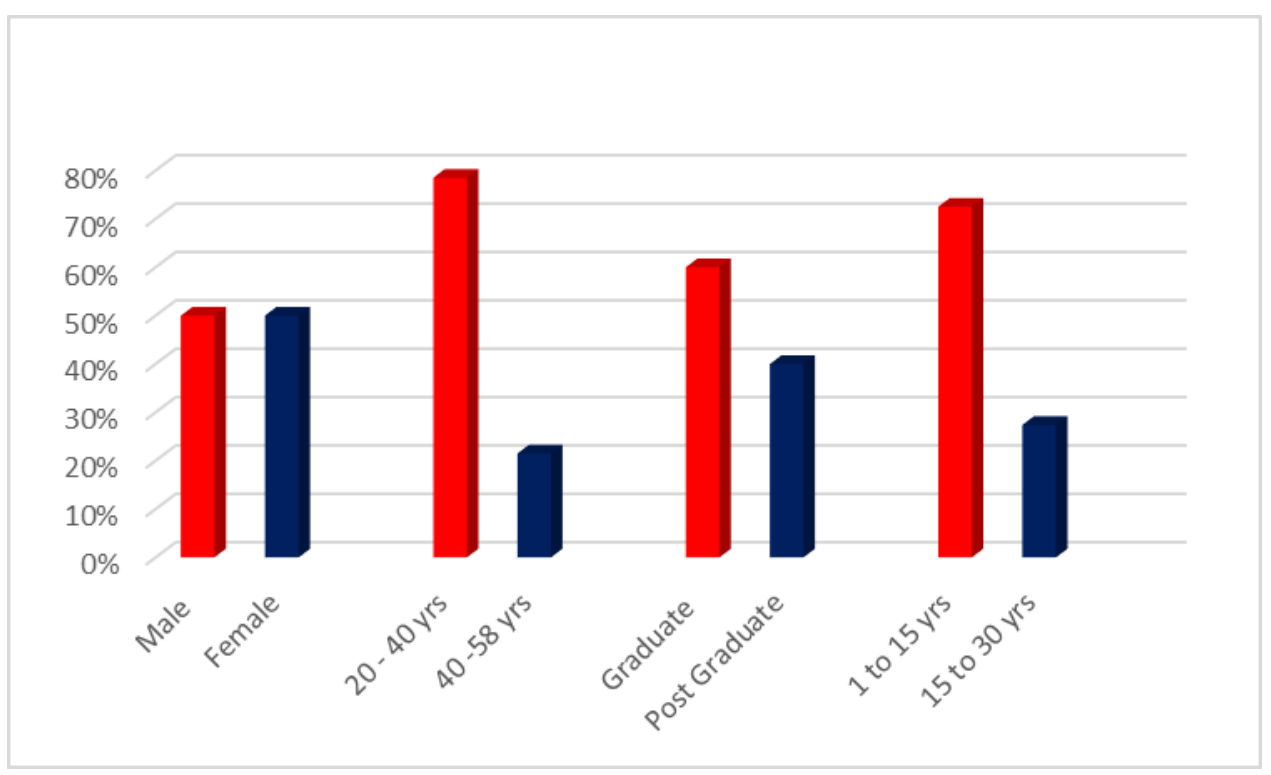

However, Figure 2 is showing the comparison of attitude of inclusive teachers towards inclusive of children with mental retardation with respect to the variables such as age group, gender, education qualification and teaching experiences within the group was found that there is no significant differences in the attitude of the subjects towards Inclusion of the children with mental retardation. Therefore, the hypothesis formulated by the researcher that there will be a significant difference in the attitude of inclusive teachers towards Inclusion of the children with mental retardation with respect to age, gender, educational qualification and teaching experience has been rejected at 0.05 level. Hence the T-Test is statistically not significant and the hypothesis is rejected.

\section{IMPLICATION OF THE STUDY}

Education of the children with mental retardation in regular class room among remote / slum areas in Nagpur has got positive response. Every student should be an integral part of the regular class room in general school as the legislation and support of policies of the Samagra Shiksha Abhiyan in an endeavor for universalization of elementary education. For educating children with mental retardation, Samagra Shiksha Abhiyan has been provided good provisions and services in the Inclusion, a beautiful source for all categories of the disability, Socio - economic 
group in the community. The parents who are unable to pay school fees to attend the school and need not to stop education (Minke, Bear, Deemer \& Griffin, 1996). Nobody should segregate due to his or her disabilities. Inclusion is the new and recent trend in the field of education system. For successful educational system the Samagra Shiksha Abhiyan has been providing training to regular school teachers in Inclusion of the Children with different disabilities such as mental retardation, hearing impairment, Cerebral Palsy, Learning disability, Visual impairment, slow learners and among others. The present study reflects that the inclusive school teachers are the good motivators and implementers for preparing children with mental retardation independent in their life. The study also reflects that there is a close collaboration between the inclusive teachers and regular class room teachers towards Inclusion with mental retardation. If there are any children with academic challenges example children with mild mental retardation, the inclusive teachers need to work with regular teachers on how to keep the students learning problems and what are the teaching strategies that helps to eradicate the academic challenges (McBrayer \& Fory, 1998; Scruggs \& Mastropieri, 1996). This study indicates that collaboration needs to be positive experiences, which includes having planning time together, collaborative teaching and learning, listening to each other concerns and making adjustments based on those concerns.

\section{CONCLUSIONS}

The present study was in fulfillment of the Master of special education in intellectual disability. The substantial co-operation and collaboration extended by the inclusive teachers in Government schools working in BRC, under Samagra Shiksha Abhiyan, Nagpur District. An attempt was made in the present study on attitude of inclusive teachers trained by Samagra Shiksha Abhiyan towards Inclusion of the children with mental retardation. Findings indicated that majority of the inclusive teachers are having positive attitude towards the Inclusion. Irrespective of the age group, gender, educational qualifications and number of years of teaching experiences and had a positive attitude towards Inclusion.

Therefore, it was concluding that the findings of the present study show that attitude of inclusive teachers towards Inclusion of the children with mental retardation were positive and the training program was given by Samagra Shiksha Abhiyan to the teachers are highly efficient and effective. The participant has suggested that there should be a training program for management in special education for the children with mental retardation and associated behavioral problems. 
This may help them to improve further total inclusion of the children with along with children without any disability is possible in an inclusive class room setting.

\section{LIMITATIONS OF THE STUDY}

In this study the researcher has been prepared questionnaire which contains three components such as attitude of Samagra Shiksha Abhiyan trained teachers towards concept of Inclusion, attitude towards strategies to improve Inclusion and attitude towards collaboration between inclusive teachers and regular teachers, if I could also prepared questionnaire on accessibility / barrier free environment in special education that may help me to analyze the attitude of the participants towards Inclusion.

\section{RECOMMENDATIONS}

The following are the recommendations for further research which enable a thorough understanding of the problem and better preparation for establishment of Inclusion system in India.

- Research study should include children with different disabilities such as Hearing impaired, Visual impaired, Orthopedic Handicapped, Multiple disability, children with behavioral problem, learning disability and others.

- Research study should include the attitude of non-inclusive teachers.

- Study on the requirement infrastructure and resources facilities for Inclusion.

\section{REFERENCE LIST}

1. Anthea, K. R. \& Tricia, M. N. (2005) A study on the importance of the awareness and communication for the inclusion of disabled students with life-limiting and life- threatening conditions in mainstream schools. British Journal of Special Education, 33(1), 15-17.

2. Bowman, P. T. (1986) Instructional strategies in main stream classrooms; prediction of the strategies teachers selects. Remedial and Special Education, 10(2), 23-30.

3. Colin, T. (2004) The search for a model of effective inclusive practice through the Inclusive School. British Journal of Special Education, 32(1), 42-45.

4. Cornoldi, Cesare, Terreni, Aiessandra, Scruggs, Thomas E. (1998) Teachers attitudes in Italy after twenty years of inclusion. Remedial and special Education, vol.19, No.6, pp.350-56. 
5. Guido, D. L. (1990). Educators' attitude towards the inclusion of severely profoundly Disabled students in Regular classrooms. Dessertation Abstract International, volume (51), No, 10.

6. Hoffman, M. A. Hale (1997) An Analysis of Inclusion in New Jersey school Districts (General Education Teachers). Dissertation Abstract International, A 58 / 05, pp.1658.

7. International League of Societies for Mentally Health (1999), http://worldcat.org/identities/lccn$\underline{\mathrm{n} 50062183 /}$

8. Fox, N. E and Ysseidyke, J. E. (1997) Implementing inclusion at the middle school level; Lessons from a negative example, Exceptional children, 64, 81-98.

9. McBrayer, P. \& Fory, K. (1998) Integrating students with disabilities in Hong Kong: classroom Teachers attitudes and beliefs, Journal of International special needs education, volume p.7 11.

10. Minke, K. M., Bear, G. G., Deemer, S. A and Griffin, S. M. (1996) Teachers experiences with inclusive classrooms: Implications for special education reform. The Journal of Special Education, 30, 152-186.

11. Paul, T. S., Deirdre, K. S., Diane, Y. H. and Todd, W. L. (2006) The sustainability of Inclusive School Reform. Exceptional Children, 72, 317-320.

12. Praisner, C. L. (2003) Attitudes of Elementary school principals towards the Inclusion of students with Disabilities. Exceptional children, volume 69, No. 2.

13. Rane, N. (1983) A theoretical frame work for understanding loss and the helping process. In R. Weston, T.Martin and Y.Anderson (Eds.). Loss and bereavement: Managing change, London.

14. Scruggs, T. E., Mastropieri, M. A. (1996) Quantitative synthesis of Survey research literature: Methodology and Validation. In T.E. Scruggs and M.A. Mastropieri (Eds.) Advances in learning and behavioural disabilities; Theoretical percepectives, IOA. Greenwich, CT; JAI, PP.209- 283.

15. Soodak, L. C., Podell, D. M. \& Lehman, L. R. (1998) Teacher, student and school attributes as predictors of teachers' responses to inclusion. The Journal of Special Education, 31, 480497.

16. Verma \& Verma, (1974) Inservice A mandated special education course and its effects on regular classroom teachers. Teacher Education and special Education. Educational, 8 (2), 5965. 
17. York, J. \& Tundidor, M. (1995) Issues raised in the name of inclusion: Perspectives of educators, parents and students. Journal of the Association for persons with severe Handicapped, 20, 31-44. 